\title{
Compressive Myeloradiculopathies in Multiple Myeloma: Clinical and Radiological Characteristics of a Series of 29 Patients
}

\author{
El Hadji Daouda Niang1*, Mbodji Ahmadou Bamba², Ka Mamadou², Fall Seynabou', \\ Seck Moussa1, Mbaye Khalifa Ababacar², Bousso Elimane1, Sarr Khadim', Faye Atoumane3, \\ Ndiaye Fatou Samba Diago', Ndiaye Moustapha ${ }^{2}$, Diop Saliou1 \\ ${ }^{1}$ Department of Haematology, Cheikh Anta Diop University, Dakar, Senegal \\ ${ }^{2}$ Department of Neurology, Cheikh Anta Diop University, Dakar, Senegal \\ ${ }^{3}$ Internal Medicine Service, Aristide Le Dantec Hospital, Cheikh Anta Diop University, Dakar, Senegal \\ Email: *elhadjidaoudaniang@gmail.com
}

How to cite this paper: Niang, E.H.D., Bamba, M.A., Mamadou, K., Seynabou, F., Moussa, S., Ababacar, M.K., Elimane, B., Khadim, S., Atoumane, F., Diago, N.F.S., Moustapha, N. and Saliou D. (2021) Compressive Myeloradiculopathies in Multiple Myeloma: Clinical and Radiological Characteristics of a Series of 29 Patients. Open Journal of Blood Diseases, 11, 133-139. https://doi.org/10.4236/ojbd.2021.114013

Received: January 17, 2021

Accepted: November 29, 2021

Published: December 2, 2021

Copyright $\odot 2021$ by author(s) and Scientific Research Publishing Inc. This work is licensed under the Creative Commons Attribution International License (CC BY 4.0).

http://creativecommons.org/licenses/by/4.0/ (c) (i) Open Access

\begin{abstract}
Introduction: Patients with multiple myeloma (MM) develop neurological complications such as root and/or spinal cord compression in at least $5 \%$ of cases. The aim of this work is to describe the clinical and radiological features of root and/or spinal cord compression occurring during multiple myeloma. Patients and Methods: We conducted a retrospective study in the Clinical Haematology Department of Dalal Jamm Hospital and the National Blood Transfusion Centre, the Neurological Clinic of Fann Hospital Centre and the Internal Medicine Department of Aristide Le Dantec Hospital in Dakar between January 2016 and December 2019. All patients whose multiple myeloma diagnosis was established according to the International Myeloma Working Group's 2014 and who had root, spinal or myeloradicular compression, were included in our study. Results: A total of 29 patients were included. The average age was 54.31 years [32 - 76 years]. The sex ratio (M/F) was 1.6. Motor deficits were the reason for consultation in $68 \%$ of the patients and spinal pains were reported by $93 \%$ of the patients. Neurological signs revealed multiple myeloma in all our patients. 25 patients $(86.2 \%)$ had paraplegia and 1 patient had tetraparesis. Hypoesthesia to a defined sensory level was noted in 8 patients (28\%). 5 patients $(17.24 \%)$ had sphincter disorders. The types of lesions showed by imaging were vertebral lysis in $100 \%$ of cases, vertebral compression in $37 \%$ of cases, and epidural infiltration in $34 \%$ of cases. 12 patients (41.37\%) had spinal compression, 14 patients $(48.27 \%)$ had root compression, and 3 patients (10.34\%) had myeloradicular compression. Spinal cord compression was most often at the dorsolumbar level (91.3\% of cases) and root compression was
\end{abstract}


mainly located in the lumbar spine (76.47\% of cases). Conclusion: Spinal and root compressions are common complications of multiple myeloma, often revealing the disease in our context. The dorsolumbar level was most often of interest in our study.

\section{Keywords}

Multiple Myeloma, Spinal Cord Compression, Root Compression, Bone Lesions

\section{Introduction}

Multiple Myeloma (MM) is a chronic lymphoproliferative syndrome characterised by monoclonal proliferation of plasma cells that invade the bone marrow and secrete monoclonal immunoglobulins [1]. Spinal myeloma disease can cause pain and potential paralysis that often leads to disability and a profound impact on prognosis, particularly radiculopathy and acute spinal cord compression (SCC) which is a medical emergency [2]. Patients with multiple myeloma (MM) develop root and/or spinal cord compression in at least $5 \%$ of cases [3].

These complications may result from various conditions such as vertebral collapse, extradural extension of the plasmacytoma from an adjacent vertebra, or more rarely intradural myeloma. The incidence of spinal disease in newly diagnosed MM was $50.7 \%$ and the incidence of SCC was $7.8 \%$ [4].

MM represents around $8.2 \%$ of cancers in Africa [5], but few studies have focused on its neurological involvement, in particular myeloradicular compression [6] [7]. The aim of this work is to describe the clinical and radiological features of root and/or spinal cord compression occurring during multiple myeloma.

\section{Patients and Methods}

We performed a retrospective descriptive study, from January 2016 to December 2019, in the Clinical Haematology Departments of Dalal Jamm Hospital and the National Blood Transfusion Centre, the Neurological Clinic of Fann Hospital Centre and the Internal Medicine Department of Aristide Le Dantec Hospital in Dakar. All patients whose multiple myeloma diagnosis was established according to the International Myeloma Working Group 2014 [8] and who had root, spinal or myeloradicular compression were included in our study.

Extensive recruitment has been carried out due to the paucity of studies on root and/or spinal cord compression. Patients with incomplete medical records and those with comorbidities that could explain these neurological conditions were not included.

We collected the following data from these patients: age, sex, time from onset of symptoms to diagnosis of spinal root or myeloradicular compression, clinical manifestations, and radiological signs on a CT scan and/or magnetic resonance imaging (MRI) of the spine. 
The statistical analysis of the data collected was carried out using Excel 2016 software.

\section{Results}

Twenty-nine (29) patients were collated, including 18 men and 11 women, for a sex ratio of 1.6. The mean age of the patients at the time of diagnosis of spinal root or myeloradicular compression was 54.31 years with extremes of 32 and 76 years and a standard deviation of 12.2 years.

The average time to diagnosis after the onset of neurological symptoms was 7 months [39 days - 14 months]. The diagnosis of multiple myeloma was established in all our patients (100\%) during the exploration of these neurological complications.

The clinical characteristics of the patients are summarised in Table 1.

Biological explorations showed normocytic normochromic anaemia in all patients with an average haemoglobin level of $9 \mathrm{~g} / \mathrm{dl}$; leukopenia was found in $3.44 \%$ of cases, thrombocytopenia in $10.34 \%$ of cases. Hyperprotidemia was observed in 24 patients (82.75\%) with an average protidemia of $103.47 \mathrm{mg} / \mathrm{l}$. Hypoalbuminemia was found in 23 patients (79.31\%) with a mean albumin level of $30.77 \mathrm{mg} / \mathrm{L}$. Hypercalcaemia was noted in 14 patients (48.27\%) with a mean serum calcium level of $103.6 \mathrm{mg} / \mathrm{L}$ and malignant hypercalcaemia in $17.24 \%$ of cases. Renal failure as assessed by urea and creatinemia (DFG) was present in 8 patients (27.58\%).

Serum protein electrophoresis revealed a monoclonal peak in gamma globulin in 22 patients (75.86\%) and in beta globulins in 5 patients (17.24\%).

Serum protein immunofixation, carried out in 9 patients, had found the IgG isotype in 5 patients and IgG A in 4 patients. The light chains were kappa in 7 patients and lambda in 2 patients.

Table 1. Clinical features at diagnosis.

\begin{tabular}{|c|c|c|}
\hline Clinical data & Number of patients & Percentage (\%) \\
\hline \multicolumn{3}{|c|}{ Functional signs } \\
\hline Motor deficit & 20 & 68 \\
\hline Paresthesias & 19 & 65.5 \\
\hline Spinal pain & 27 & 93 \\
\hline Root pain & 14 & 48.27 \\
\hline \multicolumn{3}{|c|}{ Physical signs } \\
\hline Paraplegia & 25 & 86.2 \\
\hline Tetraparesis & 1 & 3.4 \\
\hline Hypoesthesia & 8 & 25 \\
\hline $\begin{array}{c}\text { Sphincter disorders } \\
\text { (dysuria and/or constipation) }\end{array}$ & 5 & 17.24 \\
\hline
\end{tabular}


The medullogram found medullary plasmocytosis higher than $10 \%$ in all our patients.

As medical imaging, standard radiography was performed and has shown geodes in the cranial area in all patients, lysis and diffuse demineralization in the vertebral area in 7 patients. CT scan of the spine was carried out on 14 patients (48\%) and MRI on 19 patients (65\%). Among the lesions objectified, there was vertebral lysis in all patients (100\%), vertebral compaction in 9 patients (37\%), and epidural infiltration in 10 patients (34\%) (Table 2). Compressive lesions were located in the cervical area in 2 patients $(6.90 \%)$, in the dorsal area in 9 patients (31.03\%), and in the lumbar area in 18 patients (62.07). They were staggered in some patients. 12 patients (41.37\%) had spinal cord compression, 14 patients (48.27\%) had root compression, and 3 patients (10.34\%) had spinal cord and root compression. Spinal cord compression most often involves the dorsolumbar spine (91.3\% of spinal cord and myeloradicular compression cases). Root compressions were mainly located in the lumbar region $(76.47 \%$ of the cases of root and myeloradicular compressions) (Table 3).

\section{Discussion}

Multiple myeloma is a pathology of the elderly, observed around the age of sixty [8] [9] [10]. The mean age at diagnosis (54.31 years) and the male predominance noted in our series are similar to the data in the literature [10] [11]. Multiple myeloma was revealed by spinal cord and/or root compression in all our patients, attesting to the late diagnosis in our region, generally at the complication stage.

The reasons for consultation are dominated by the spinal pain noted in $93 \%$ of our patients. This pain, reported in $84.9 \%$ of cases by Jung et al. [11], can be explained by vertebral osteolysis with or without compression.

Table 2. Frequency of different types of spinal lesions in patients.

\begin{tabular}{ccc}
\hline Type of injury & Number of patients & Percentage (\%) \\
\hline Spinal lysis & 29 & 100 \\
Spinal compression & 9 & 37 \\
Epidural Infiltration & 10 & 34 \\
\hline
\end{tabular}

Table 3. Frequency of spinal root and myeloradicular compressions with their topographical distribution.

\begin{tabular}{ccccc}
\hline Type & Cervicale & Dorsale & Lumbar & Total \\
\hline Spinal cord compression & 2 & 5 & 5 & $12(41.37 \%)$ \\
Myeloradicular compression & 0 & 2 & 1 & $3(10.34 \%)$ \\
Root compression & 0 & 2 & 12 & $14(48.27 \%)$ \\
\hline
\end{tabular}


In our study, paraplegia was noted in 25 patients (86.2\%), hypoesthesia in $28 \%$ of cases, and sphincter disorders were noted in $17.24 \%$ of cases. In contrast to these results, Jung et al. [11] found $35.8 \%$ of cases with motor deficit, 50.9\% with sensory impairment, and $11.3 \%$ with sphincter disorder. This observed difference could be explained by the delay in diagnosis observed in our study, the size of the cohort, and the study of myeloradicular compression compared to Jung's study [11] where the population size was larger and his study focused on spinal cord compression.

Biologically, anaemia is the most common haematological manifestation during multiple myeloma. It was present in all our patients. However, anemia's severity differs from study to study [10] [12]. Other biological data are similar to those reported in the other African series [9] [11] [13].

On imaging, the radiological lesions found were identical to the data in the literature [14] [15] and bone lysis was found in all our patients. Packing was less frequent and epidural infiltration was found more frequently in our series than in that of Fall et al. [13] due to the fact that imaging (MRI) is becoming increasingly accessible in our region.

Root compression represented $48.27 \%$ of the cases in our study. Root pain results from nerve compression by direct extension of the vertebral plasmocytoma lesion, from foraminal stenosis secondary to the collapse of the bone itself or, more rarely, from leptomeningeal disease. Magnetic resonance imaging (MRI) of the affected area will usually clarify the etiology and guide therapy [3]. Compressive lesions, whether medullary or root lesions, had a predominantly lumbar topography, unlike the study by Bouatay et al. in Tunisia [12] where dorsal damage was predominant.

Medullary compression accounted for $41.37 \%$ with dorsal topography in most cases. This location was most often found in the literature [16]. Spinal cord compression is present in at least $5 \%$ of patients at some point during their disease [3] and accounts for $83 \%$ of patients at diagnosis in the study by Jung et al. [16]. Epidural extraosseous multiple myeloma without lysis or spinal compression was not found in our study.

The incidence of spinal cord compression related to multiple myeloma worldwide has decreased over the last decade, from $10 \%$ before 1960 to $3.8 \%$ between 1960 and 1970 to less than $2 \%$ in the late 1980 [3]. However, it remains high in our study with a prevalence of $41.37 \%$, in contrast to studies in Africa [11] [13]. This could be explained on the one hand by the scarcity of specific studies on the neurological manifestations related to myeloma and on the other hand by a delay in diagnosis.

\section{Conclusion}

Spinal and root compressions are common complications of multiple myeloma, often revealing the disease in our context. The dorsolumbar level was most often of interest in our study. Delayed diagnosis of its complications contributes to the 
poor prognosis of multiple myeloma. However, early diagnosis of myeloma through a detailed disease history and careful physical examination in our context would allow for early management before the onset of these neurological complications.

\section{Conflicts of Interest}

The authors declare no competing interests.

\section{Authors' Contributions}

All authors have read and agreed to the final manuscript.

\section{References}

[1] Manier, S. and Leleu, X. (2011) Myélome multiple: Diagnostic clinique et perspective de traitement. Recommandations de l'International Myeloma Working Group (IMWG). Immuno-analyse \& Biologie Spécialisée, 26, 125-136. https://doi.org/10.1016/j.immbio.2011.04.001

[2] Yavas, G. (2016) The Management of Spinal Cord Compression in Multiple Myeloma. Annals of Hematology \& Oncology, 3, 1090.

[3] Dispenzieri, A. and Kyle, R.A. (2005) Neurological Aspects of Multiple Myeloma and Related Disorders. Best Practice \& Research Clinical Haematology, 18, 673-688. https://doi.org/10.1016/j.beha.2005.01.024

[4] Chen, B., Cai, L. and Zhou, F. (2020) Management of Acute Spinal Cord Compression in Multiple Myeloma. Critical Reviews in Oncology/ Hematology, 160, Article ID: 103205. https://doi.org/10.1016/j.critrevonc.2020.103205

[5] Alao, O.O., Bazuaye, G.N., Halim, N.K. and Omoti, C.E. (2010) The Epidemiology of Hematological Malignancies at the University of Benin Teaching Hospital: A Tern-Year Retrospective Study. International Journal of Epidemiology, 9, 34-45. https://doi.org/10.5580/1fbb

[6] Doualla-Bija, M., Ndongho, E.N., Oben, D.T., et al. (2014) Musculoskeletal Presentation of Multiple Myeloma at General Hospital Douala, Cameroon. East African Medical Journal, 91, 311-316.

[7] Husein, A., Siddig, A., Yousif, O., et al. (2011) Neurological Manifestaions among Sudanese Patients with Multiple Myeloma. Sudan Journal of Medical Sciences, 6, 167-172.

[8] Rajkumar, S.V., Dimopoulos, M.A., Palumbo, A., et al. (2014) International Myeloma Working Group Updated Criteria for the Diagnosis of Multiple Myeloma. The Lancet Oncology, 15, E538-E548. https://doi.org/10.1016/S1470-2045(14)70442-5

[9] Nnonyelum, O.N., Anazoeze, M.J., Eunice, N.O., et al. (2015) Multiple Myeloma in Nigeria: A Multi-Centre Epidemiological and Biomedical Study. The Pan African Medical Journal, 22, 292. https://doi.org/10.11604/pamj.2015.22.292.7774

[10] Ndiaye, F., Pouye, A., Fall, S., et al. (2011) Présentation clinique du myélome multiple à Dakar (Sénégal): à propos de 71 observations. Journal Africain du Cancer, 3, 8-11. https://doi.org/10.1007/s12558-010-0126-9

[11] El Husseiny, N.M., Kasem, N., El Azeeim, H.A., et al. (2014) Multiple Myeloma: A Descriptive Study of 217 Egyptian Patients. Annals of Hematology, 93, 141-145.

https://doi.org/10.1007/s00277-013-1849-3 
[12] Bouatay, A., Hizem, S., Ben Youssef, Y., et al. (2013) Myélome multiple: Aspect clinique, diagnostic biologique et pronostic. Immuno-analyse \& Biologie Spécialisée, 28, 30-35. https://doi.org/10.1016/j.immbio.2012.09.001

[13] Fall, S., Dieng, F., Diouf, C., et al. (2017) Profil diagnostique et évolutif du myélome multiple au Sénégal: étude monocentrique de 2005 à 2016. The Pan African Medical Journal, 27, 262. https://doi.org/10.11604/pamj.2017.27.262.13164

[14] Ngolet, L.O., Kocko, I., Atipo, F.O.G., et al. (2016) Le myélome multiple symptomatique à Brazzaville: à propos de 40 cas. Annales de P Université Marien NGOUABI, 16, 273-274.

[15] Kodjo, K. (2014) Profile of Multiple Myeloma among Rheumatology Inpatients in Lomé (Togo). Revue Marocaine de Rhumatologie, 27, 48-53.

[16] Jung, H.A., Cho, S.H., Kim, S.J., et al. (2014) Spinal Cord Compression in Multiple Myeloma: A Single Center Experience. Leukemia \& Lymphoma, 55, 2395-2397. https://doi.org/10.3109/10428194.2014.880429 